\title{
Clinical Data Analysis of Nodular Erythema
}

\author{
Fu Shuying ${ }^{1}$ Liao Xuankai ${ }^{2}$ Chen Hongda ${ }^{3, *}$
}

\begin{abstract}
${ }^{1}$ Department of Dermatology, The Seventh Affiliated Hospital, Sun Yat-sen University , Guangdong, China. Email:657154234@qq.com; 'Department of Pathology, The Seventh Affiliated Hospital, Sun Yat-sen University , Guangdong, China. Email:liaoxk5@mail.sysu.edu.cn; ${ }^{3}$ Department of Traditional Chinese Medicine, The Seventh Affiliated Hospital, Sun Yat-sen University, Guangdong, China.Email:41370711@qq.com. *Corresponding author:Email:41370711@qq.com, https://orcid.org/0000-0001-8969-1925.
\end{abstract}

Article History Received 20 January 2021 Accepted 25 January 2021 Published 31 March 2021

Cite this Article Fu Shuying, Liao Xuankai, Chen Hongda. Clinical Data Analysis of Nodular Erythema [J].Medical Research, 2021.3(1):6-11, http://dx.doi.org/10.6913/MRHK.202103_3(1).0002

Copyright (C) 2021 Creative Publishing Co., Limited. All rights reserved.Email:mrhk26640333@gmail.com.

Abstract

Objective Investigate the relationship between clinical manifestations and pathological changes of Erythema Nodosum.

Subjects and Methods 94 patients diagnosed with erythema nodosum were collected by the clinical data. Results Five etiologies were treated, which was found by $\mathrm{p}<0.05$. It shows that the recovery within one month was statistically significant. 9 of 94 patients were diagnosed with TB infection. 7 patients were found with multiple nuclear giant cells infiltration in the HE pathological films.

Conclusion The treatment of erythema nodosum is mainly due to treatment. It shows that there are multinucleated giant cells in the pathology, which may be suspected of tuberculosis infection.

Keywords Erythema Nodosum; Mycobacterium Tuberculosis; Pathology

\section{Introduction}

The pathological features of erythema nodosum showed the change of cutaneous panniculitis. At present, the etiology is unknown and considered to the following factors:1.infection: bacteria, viruses, fungi, mycoplasma, chlamydia, etc. Mycobacterium tuberculosis and other mycobacteria are considered by rare infected pathogens; 2.connective tissue diseases related; 3.endocrine system disorders; 4.drugs; 5.tumors; 6.pregnancy ${ }^{[1]}$.

China is a country with high incidence of Mycobacterium tuberculosis, and the relationship between Mycobacterium tuberculosis and nodular erythema deserves attention ${ }^{[2] .}$

We analyse the relationship between erythema nodosum and Mycobacterium tuberculosis from clinical data, and further provides reference for clinical diagnosis and treatment.

\section{Materials and methods}

Ninety-four patients with erythema nodosum were diagnosed in the dermatology department of our 
hospital from 2003 to 2018.

Methods of retrospective investigation and analysis were used to record the sex, age of diagnosis, clinical manifestation of tuberculosis, history of tuberculosis (history of tuberculosis, history of contact with tuberculosis), and methods of clinical examination for tuberculosis screening.

China promulgated the Classification of WS 196-2017 Tuberculosis and the Diagnostic criteria of WS288-2017 Tuberculosis on 9 November, 2017.

\section{Statistical analyses}

The obtained data were analyzed with the Statistical Package for the Social Sciences (SPSSVR ) version 19.0 (IBM Corporation, Armonk, NY, USA). Discrete analysis of age distribution and chi-square test of treatment principles and efficacy. Statistical significance was defined as p values of $<0.05$.

\section{Results}

Table 1 Age distribution of 94 patients

\begin{tabular}{lllll}
\hline Age of onset & $<18$ & $18-44$ & $44-59$ & $\geq 60$ \\
\hline & 7 & 55 & 21 & 11 \\
Female n (\%) & $5(71.4)$ & $39(70.9)$ & $19(90.5)$ & $9(81.8)$ \\
Mean age & 13.0 & 34.4 & 50.9 & 72.8 \\
\hline
\end{tabular}

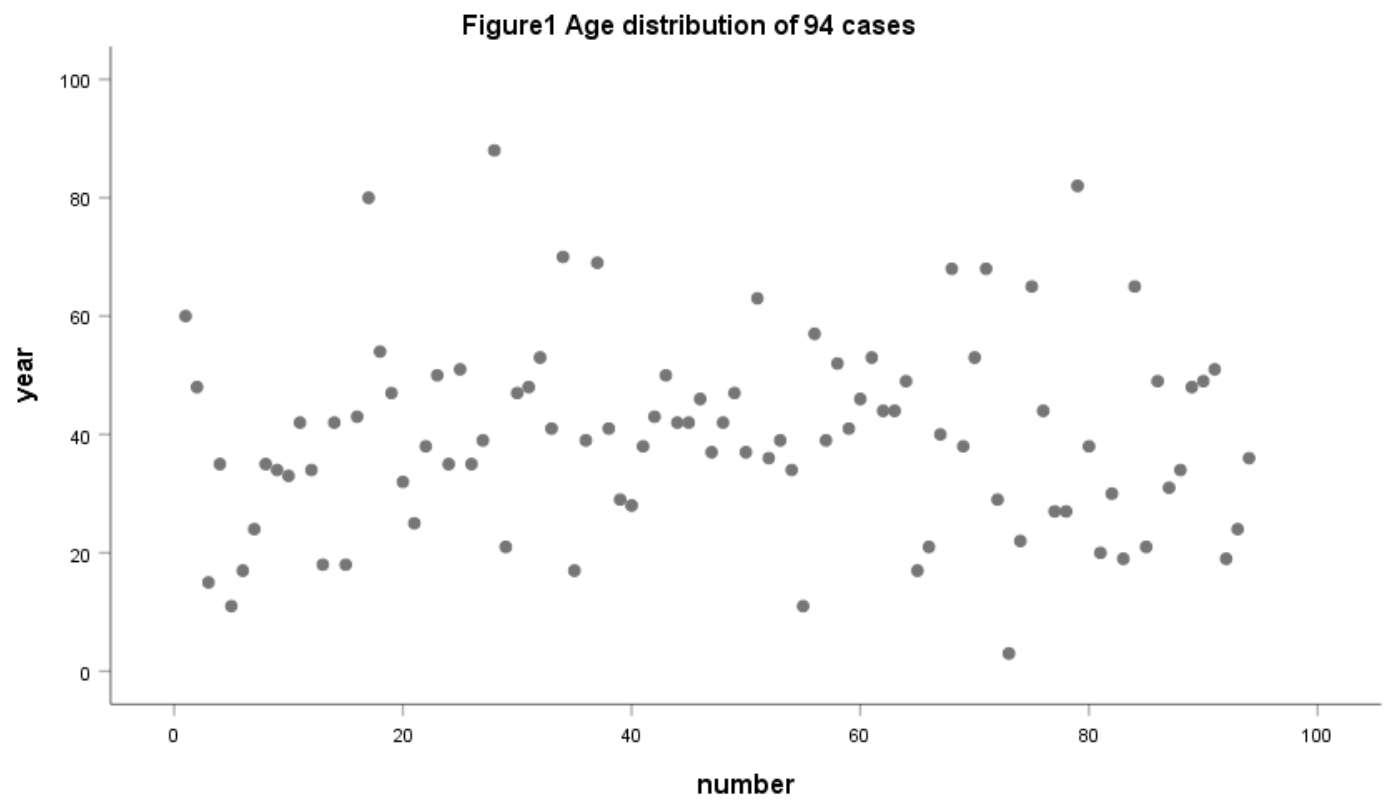

Table 2 Analysis of pathological sites in patients with nodular erythema

\begin{tabular}{llllllll}
\hline $\begin{array}{l}\text { Pathological } \\
\text { site }\end{array}$ & Foot & Leg & Thigh & Limbs & $\begin{array}{l}\text { Upper } \\
\text { Limbs }\end{array}$ & $\begin{array}{l}\text { Popliteal } \\
\text { Fossa }\end{array}$ & $\begin{array}{l}\text { Oral } \\
\text { Cavity }\end{array}$ \\
\hline & 2 & 40 & 25 & 20 & 5 & 1 & 1 \\
\hline
\end{tabular}

94 patients were distributed between 18 and 59 years old, indicating that the prone population was among the young and middle-aged patients(table 1 and figure 1). The lesions were mainly distributed in legs. But we further analysis the site of erythema nodosum involving the limbs, but did not mention the specific sites that could be involved.This study can be seen that there are a variety of sites, such as mouth, popliteal 
Fu Shuying, Liao Xuankai, Chen Hongda. Clinical Data Analysis of Nodular Erythema Medical Research ISSN 2664-0333 eISSN 2664-0341 Volume 3 Issue $1 \quad$ http://dx.doi.org/10.6913/MRHK.202103_3(1).0002

fossa, oral cavityand so on(table 2).

Table 3 Summary of laboratory findings, treatment options and prognosis of patients with nodular erythema

\begin{tabular}{|c|c|c|c|}
\hline diagnosis & number & treatment & Healing (30d) \\
\hline Bacteria except TB suggested & 15 & Antibiotics & 7 \\
\hline TB infection & 12 & Anti-tuberculosis drugs & 8 \\
\hline $\begin{array}{l}\text { suggesting connective tissue } \\
\text { diseases }\end{array}$ & 12 & $\begin{array}{l}\text { Hormone/immune } \\
\text { inhibitor/hormone } \\
\text { immunosuppressant }\end{array}$ & 9 \\
\hline $\begin{array}{c}\text { No infections and connective } \\
\text { tissue diseases }\end{array}$ & 24 & $\begin{array}{l}\text { Hormone/immune } \\
\text { inhibitor/hormone } \\
\text { immunosuppressant }\end{array}$ & 19 \\
\hline No laboratory related data & 30 & Hormone & 30 \\
\hline
\end{tabular}

The results of laboratory examination showed that the etiology of 94 patients was diversed (table 3). The above five diagnostic results were analyzed, and after the corresponding treatment plan was carried out, the SPSS statistics were carried out, and the $p$ was found to be $0.009(<0.05)$, which indicated that the treatment was statistically significant within one month.

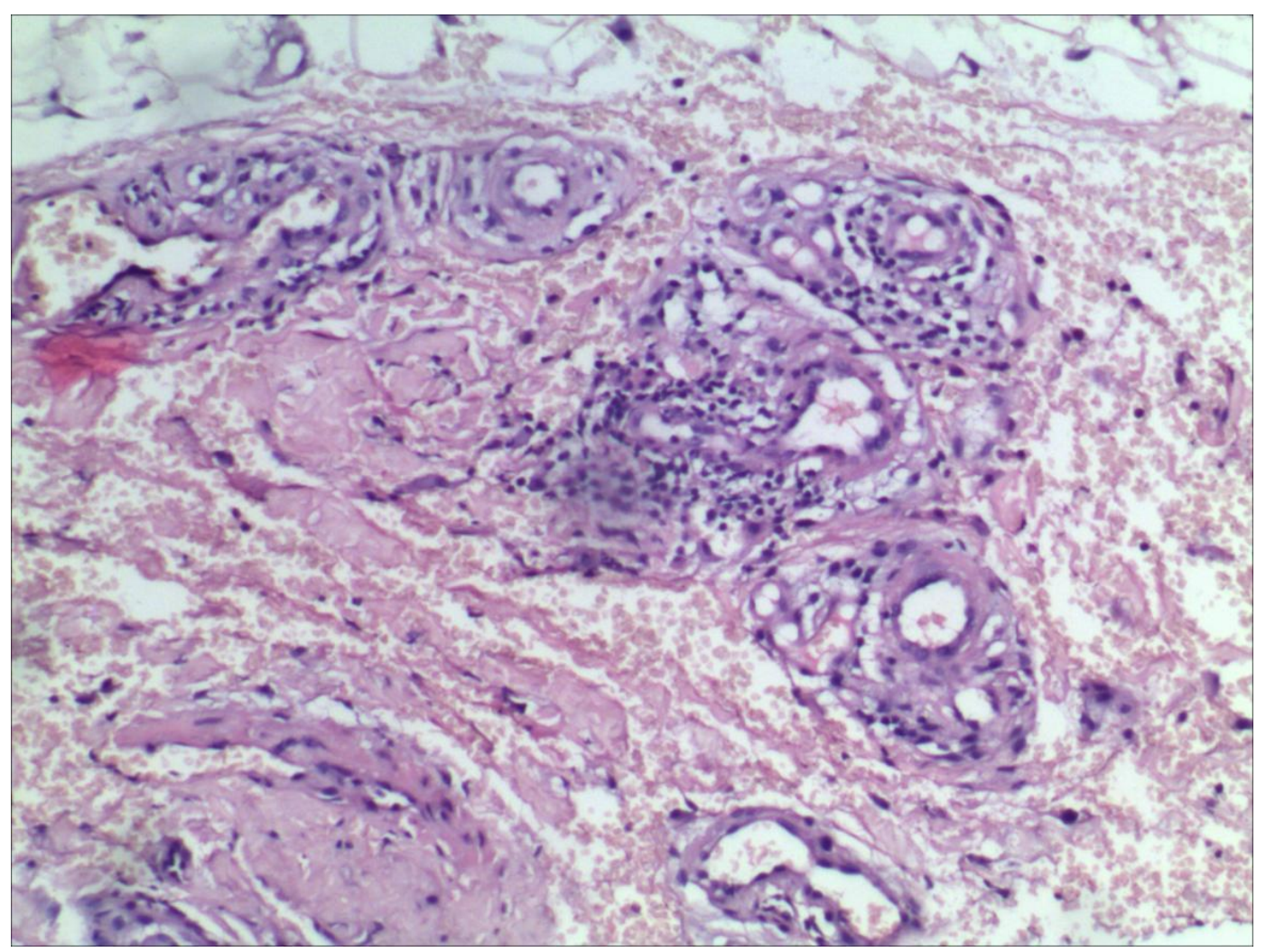

Fig2: Fat lobular necrosis at intervals, intralobular inflammatory cell infiltration, small vessel wall degeneration necrosis, lumen blockage. (HE,10X10). 


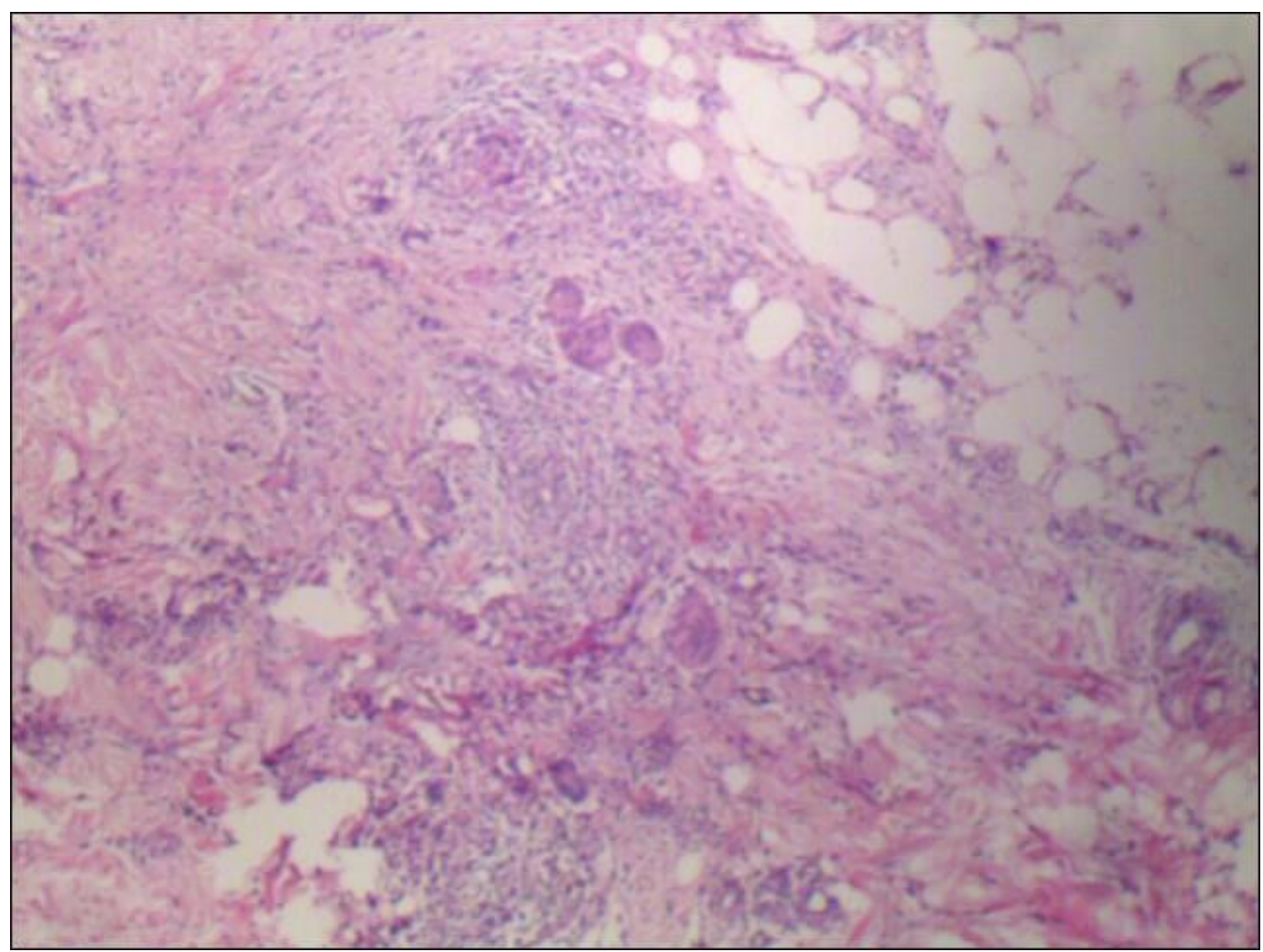

Fig3: partial fat lobular necrosis, and polynuclear giant cells (HE 10X10).

HE histology of all selected patients showed changes in cutaneous panniculitis. Adipose lobular septal fibrous tissue proliferation and a large number of inflammatory cell infiltration were observed in the HE pathology of the patients. Adipose interlobular septa were found with cells such as lymphocytes and histiocytes and neutrophils from 85 patients. The remaining 9 cases indicated TB infection, of which 7 patients had suggesting multiple nuclear giant cell infiltration in the HE pathological films.

\section{Discussion}

China has a high incidence of tuberculosis. Among many diseases with unknown etiology, Mycobacterium tuberculosis is associated with the incidence of these diseases. Infection of Mycobacterium tuberculosis has been paid more and more attention in recent years ${ }^{[3]}$. In particular, some authors believe that Mycobacterium tuberculosis is considered to be a factor of erythema nodosum ${ }^{[4]}$.

At present, it is believed that the pathogenesis of nodular erythema is: 1, foreign antigens cause delayed hypersensitivity; 2, antigens stimulate the body to produce antigen-antibody complexes, antigen-antibody complexes are deposited in the vascular wall, and local inflammatory reactions are caused by complement pathway ${ }^{[5]}$.

We analyzed the clinical data of 94 selected patients, and found that the onset age of the selected patients was between 18 and 59 years old, and the female patients were significantly more than the male, which may be related to estrogen and progesterone secretion ${ }^{[6]}$. It might also be related to the treatment of the disease in female patients than in male patients. Though we can't trace the specific location of each patient, we could not only judge the pathological sites of the patient at that time. We only knew that the sites of 
nodular erythema were diverse. Perhaps exogenous substances can be in different parts because of leukocyte fragmentation vasculitis ${ }^{[7]}$.

Although the etiology of nodular erythema is unknown, there are several clinical causes: infection-related, connective tissue disease-related, unrelated infection and connective tissue disease ${ }^{[8]}$. Treatment can improve the cure rate of the disease and guide the clinic. According to the previous literature, the possibility of nodular erythema caused by TB infection is very low. But taking results of 94 patients into account, we can realize that the number of patients with Mycobacterium tuberculosis is not in the minority.

HE histopathological films of 94 patients were analyzed again. There were no caseous necrosis and Langerhans cells ${ }^{[9]}$ and no obvious tuberculosis infection in the pathological changes of 94 patients. However, we find that some patients have local tissue necrosis and occasionally polynuclear giant cells ${ }^{[10]}$ in $\mathrm{HE}$ pathological films. The results are similar to those reported in the literature, indicating that the inflammatory reaction between the multinucleated giant cells and lobules can occur on the histopathology of patients with tuberculous erythema. According to the results, we can see that there were polynuclear giant cells infiltration on the HE histopathological films of patients with erythema nodosum in the future, suggesting that the pathogenesis of this patient may be related to the infection of tuberculous bacteria.

Due to the lack of understanding between Mycobacterium tuberculosis and nodular erythema and the lack of relevant laboratory data, some patients can further expand the number of cases in the future. And the discovery of nodular erythema as far as possible night-related screening TB laboratory examination, it is more perfect.

\section{Acknowledgements}

The authors would like to thank all the participants in the study. Authors' contributions: S-Y.Fu and X-K Liao wrote the draft; X-K Liao and H-D Chen proposed and designed the study, and S-Y.Fu, X-K Liao, H-D Chen, S-Y.Fu and X-K Liao collected the clinical data. S-Y.Fu, X-K Liao, H-D Chen analyzed the data.

\section{Disclosure statement}

The authors report no conflicts of interest. The authors alone are responsible for the content and writing of this article.

\section{Funding}

This work was supported by the Project of Traditional Chinese Medicine of Guangming District of Guangdong Province of China [NO.GM2019020028].

\section{Reference}

[1] Leung, A., K.F. Leong and J.M. Lam, Erythema nodosum. World J Pediatr, 2018. 14(6): p. 548-554.

[2]Harding, E., WHO global progress report on tuberculosis elimination. Lancet Respir Med, 2020. 8(1): p. 19.

[3]Banuls, A.L., et al., Mycobacterium tuberculosis: ecology and evolution of a human bacterium. J Med Microbiol, 2015. 64(11): p. 1261-1269. 
[4]Molina-Ruiz, A.M. and L. Requena, [Erythema nodosum]. Med Clin (Barc), 2016. 147(2): p. 81-6.

[5]Schwartz, R.A. and S.J. Nervi, Erythema nodosum: a sign of systemic disease. Am Fam Physician, 2007. 75(5): p. 695-700.

[6]Varas, P., et al., [Erythema nodosum: Analysis of 91 hospitalized patients]. Rev Med Chil, 2016. 144(2): p. $162-8$.

[7]Velter, C. and D. Lipsker, [Cutaneous panniculitis]. Rev Med Interne, 2016. 37(11): p. 743-750.

[8]Freeman, H.J., Erythema nodosum and pyoderma gangrenosum in 50 patients with Crohn's disease. Can J Gastroenterol, 2005. 19(10): p. 603-6.

[9]Pezzella, A.T., History of Pulmonary Tuberculosis. Thorac Surg Clin, 2019. 29(1): p. 1-17.

[10]Machado, D., I. Couto and M. Viveiros, Advances in the molecular diagnosis of tuberculosis: From probes to genomes. Infect Genet Evol, 2019. 72: p. 93-112. 